\title{
A Qualitative Analysis of Implementation of Antimicrobial Stewardship at 3 Academic Hospitals: Understanding the Key Influences on Success
}

\author{
Lianne Jeffs, Nisha Thampi, Maria Maione, Marilyn Steinberg, Andrew M Morris, \\ and Chaim M Bell
}

\begin{abstract}
Background: Inappropriate use of antimicrobials is linked to the development and spread of drug-resistant pathogens and is associated with increased morbidity, mortality, lengths of hospital stay, and health care costs. "Antimicrobial stewardship" is the umbrella term for an evidencebased knowledge translation strategy involving comprehensive quality improvement activities to optimize the use of antimicrobials, improve patient outcomes, reduce the development of antimicrobial resistance and hospital-acquired infections such as Clostridium difficile, and decrease health care costs.

Objective: To assess the perceptions and experiences of antimicrobial stewardship program leaders in terms of clinicians' attitudes toward and behaviours related to antimicrobial prescribing.

Methods: In this qualitative study, semistructured interviews were conducted with 6 antimicrobial stewards (2 physicians and 4 pharmacists) at 3 academic hospitals between June and August 2013.

Results: The following 3 key themes emerged from the interviews: getting the right people on board, building collegial relationships, and rapidly establishing a track record. The study results elucidated the role and mechanisms that the program leader and other antimicrobial stewards used to influence other clinicians to engage in effective utilization of antimicrobials. The results also highlighted the methods employed by members of the antimicrobial stewardship team to tailor their strategies to the local context and to stakeholders of participating units; to gain credibility by demonstrating the impact of the antimicrobial stewardship program on clinical outcomes and cost; and to engage senior leaders to endorse and invest in the antimicrobial stewardship program, thereby adding to the antimicrobial stewards' credibility and their ability to influence the uptake of effective antimicrobial use.

Conclusions: Collectively, these results offer insight into processes and mechanisms of influence employed by antimicrobial stewards to enhance antimicrobial use among clinicians, which can in turn inform future implementation of antimicrobial stewardship and strategies for organizational change in hospitals.
\end{abstract}

Keywords: antimicrobial stewardship implementation, mechanisms of influence, processes, qualitative research

Can J Hosp Pharm. 2015;68(5):395-400

\section{RÉSUMÉ}

Contexte : L'utilisation inappropriée d'antimicrobiens est liée au développement et à la propagation de pathogènes résistants aux médicaments, en plus d'être associée à une augmentation de la morbidité, de la mortalité, de la durée du séjour à l'hôpital et des coûts des soins de santé. "Gérance des antimicrobiens " est le terme générique désignant une stratégie d'application des connaissances fondée sur des données probantes qui comporte des activités exhaustives d'amélioration de la qualité pour : optimiser l'utilisation des antimicrobiens, améliorer les résultats thérapeutiques, freiner l'émergence de la résistance aux antimicrobiens, diminuer les infections nosocomiales (notamment par Clostridium difficile) et réduire les coûts des soins de santé.

Objectif : Évaluer les perceptions et l'expérience des chefs des programmes de gérance des antimicrobiens par rapport à l'attitude et aux habitudes des cliniciens quant à la prescription d'antimicrobiens.

Méthodes : Dans la présente étude qualitative, des entrevues semistructurées ont été réalisées auprès de 6 responsables de la gérance des antimicrobiens ( 2 médecins et 4 pharmaciens) dans 3 centres hospitaliers universitaires entre juin et août 2013.

Résultats : Les entrevues ont permis de dégager trois thèmes clés : obtenir le concours des bonnes personnes, établir des relations collégiales et démontrer un bilan convaincant le plus rapidement possible. Les résultats de l'étude ont permis d'expliquer le rôle joué par les chefs de programme et autres responsables de la gérance des antimicrobiens ainsi que les mécanismes qu'ils ont utilisés pour influencer les autres cliniciens à entreprendre une utilisation réellement efficace des antimicrobiens. Les résultats ont aussi mis en évidence les méthodes employées par des membres de l'équipe de gérance des antimicrobiens pour adapter leurs stratégies en fonction du contexte local et des parties prenantes des services participants; pour obtenir davantage de crédibilité en démontrant les effets du programme sur les résultats cliniques et les coûts; et pour amener les hauts dirigeants à soutenir le programme et à y investir, ce qui augmente la crédibilité des responsables de la gérance des antimicrobiens et accroît leur capacité à influencer l'adoption d'une utilisation réellement efficace des antimicrobiens.

Conclusions : Ensemble, ces résultats aident à mieux comprendre les méthodes et mécanismes d'influence employés par les responsables de la gérance des antimicrobiens pour faire en sorte que les cliniciens fassent un meilleur usage des antimicrobiens, ce qui permettra ensuite de guider 
la mise en œuvre d'une future gérance des antimicrobiens et de stratégies relatives au changement organisationnel dans les hôpitaux.

Mots clés : mise en œuvre de programmes de gérance des antimicrobiens, mécanismes d'influence, méthodes, recherche qualitative

\section{INTRODUCTION}

$\mathrm{R}$ educing the morbidity and mortality from infectious diseases is of global interest and is a priority safety and quality issue..$^{1-3}$ Nevertheless, antimicrobials are prescribed for about one-third of hospitalized patients, often inappropriately. ${ }^{4-7}$ In intensive care units (ICUs), antimicrobials are prescribed for roughly $70 \%$ of patients. ${ }^{7}$ Inappropriate antimicrobial use is linked to the development and spread of drug-resistant pathogens, ${ }^{8,9}$ which are associated with increased morbidity, mortality, lengths of hospital stay, and health care costs. ${ }^{1-3,7,8,10-13}$ With antimicrobial resistance rates rising and few new antimicrobials being developed, antimicrobial stewardship programs are increasingly employed as a key strategy for optimizing antimicrobial prescribing in a variety of patient care settings. ${ }^{1-3,14-17}$

"Antimicrobial stewardship" is the umbrella term for an evidence-based knowledge translation strategy involving comprehensive quality improvement activities. Collectively, these activities aim to optimize the use of antimicrobials, improve patient outcomes, reduce the development of antimicrobial resistance and hospital-acquired infections such as Clostridium difficile, and decrease health care costs. ${ }^{1-3,18,19}$ Antimicrobial stewardship programs are interdisciplinary and may involve physicians, pharmacists, infection preventionists, nurses, other health care providers, and support personnel. ${ }^{1-3}$ Interdisciplinary teams include stewards, who are knowledgeable about the relationship between antimicrobial use and resistance and who are responsible for influencing the use of these drugs. ${ }^{20}$

The incorporation of stewards in clinical care is rooted in what is known about key opinion leaders creating change through their social influence within a group. ${ }^{21,22}$ Such key opinion leaders facilitate the uptake of evidence-based practice as part of a multipronged intervention. ${ }^{23,24}$ Although literature about key opinion leaders is available, empirical evidence specific to how antimicrobial stewards influence the uptake of evidencebased use of antimicrobials is limited. In this context, a study was undertaken to examine the processes and mechanisms employed by antimicrobial stewards to influence antimicrobial use in the ICU environment.

\section{METHODS}

This study used a qualitative design with semistructured interviews. Ethics approval was obtained from the Mount Sinai and University Health Network research ethics boards. Antimicrobial stewards involved in an antimicrobial stewardship program covering the ICUs of 3 teaching hospitals located in Toronto, Ontario (Mount Sinai [1 site] and University Health Network [2 sites]), were invited by a research coordinator (via e-mail) to participate in an interview. Written informed consent was obtained before conducting each interview.

Two experienced qualitative research coordinators conducted interviews with the antimicrobial stewards (project leaders) between June and August 2013. An interview guide developed specifically for this study was used to examine the project leaders' perspectives on their experiences with implementing the antimicrobial stewardship program. Before conducting any interviews, the research coordinators met with one of the senior investigators (L.J.) to review the interview guide, to ensure consistency in the conduct of the interviews. Interviews were conducted until saturation of themes and categorical data were achieved and no new insights were derived from successive interviews.

The interviews were audiotaped and transcribed for analysis. The data were analyzed using a directed content analysis approach. ${ }^{25,26}$ Specifically, the analytical process involved 2 investigators (L.J., N.T.) independently reviewing all transcripts line by line to identify sections of text that could serve as codes, which were then "rolled up" to create categories (by consensus). From this step, a coding schema was created. Data collection and analysis were iterative, whereby themes, subthemes, and subcategories were added to reflect variations in the data. As part of the iterative analytical process and as a strategy to ensure methodologic rigour, the original transcripts were reviewed using the emergent coding schema.

\section{RESULTS}

\section{Sample Characteristics}

Six antimicrobial stewards were interviewed ( 2 physicians and 4 pharmacists), including the director of the program, all of whom had been working in the areas of infectious disease and antimicrobial stewardship for 2 to 20 years. Two of the antimicrobial stewards worked primarily with immunocompromised populations and the others in the ICUs..

\section{Themes}

The following 3 key themes emerged from the interviews: getting the right people on board, building collegial relationships, and rapidly establishing a track record. 


\section{Getting the Right People on Board}

The first theme reflected the process and mechanisms in which the director and stewards of the antimicrobial stewardship program engaged to get the right people on board throughout the organization. All participants identified the key role that the program director played in securing senior management support for the program. The program director was able to leverage a leadership role in a multisite research study and the Required Organizational Practice for antimicrobial stewardship programs recently released by Accreditation Canada. ${ }^{27}$ This program leader was respected within the organization and was viewed as a "great person to tap into" to solve problems or offer advice to other antimicrobial stewards. The stewards described how the team was built and noted that the program director was purposive in recruiting the right personnel as antimicrobial stewards on the project team, people who were "knowledgeable", "resourceful", "collaborative", and "self-reflective" with a "thick skin". The antimicrobial stewards perceived having a strong program director and executive endorsement as providing "added weight" to get "buy-in" from staff in relation to appropriate antimicrobial use. This perception is exemplified by the following quotations:

Somebody who is seen as a physician leader within that institution, someone who other people within the institution have a lot of respect for and see as a leader and if that person says "yes this is great" then especially in small institutions you are going to get more of a buyin from other clinicians to do that. They are also a great person to tap into when someone is being a bit of an outlier, someone to go and have that locker room chat with and say "I think this is a good idea and I think this is why I buy into it" as opposed to it coming from somebody that they don't know and have that relationship with. [Participant 5]

The first thing is get the right people who will comprise your team. By far it all has to do with people. If you're starting up a program and you can choose who's going to be in your program, make sure you get very good people. The second thing is get whoever you need to support you, the senior leadership, and local leadership, get them on board early and get them in the know and members of the team feeling empowered and that they own some of the success of the programs that they're working on, projects that they're working on. [Participant 4]

[In response to the question of what are the attributes of an antimicrobial steward] I think having a thick skin. Not be afraid that you will be yelled at. I'm used to it because where I was working before people were very resistant to antimicrobial stewardship. But, apart from that, I think it's just perseverance. Be resourceful, problem solve and self-reflect. I think that's very important especially when it comes to interprofessional collaboration. Hav[ing] strong self-reflection skills I think is very important to be an antimicrobial steward. [Participant 3]

\section{Building a Collegial Relationship}

In addition to having cost and clinical outcomes data, building relationships with clinicians in each ICU was also identified as a key process for the antimicrobial stewards. This second theme describes how the antimicrobial stewards used several mechanisms to build relationships with the ICU clinicians. Often this occurred over time, both formally (e.g., during rounds and face-to-face meetings) and informally (e.g., having coffee or hallway conversations). The antimicrobial stewards also described making the process of implementing an antimicrobial stewardship program a "we" dynamic instead of a "you" and "us" dynamic. Specifically, antimicrobial stewards emphasized that they needed to create conditions for local ownership by the prescribers, for prevention of power struggles, and for celebration of successes. This process involved the antimicrobial stewards not viewing themselves as the experts, but rather using the interactions and exchanges between themselves and the ICU clinicians as opportunities for all to learn. The following narrative examples highlight this subtheme:

When I develop relationships with colleagues for the purpose of getting buy-in, I spend time meeting with them. Usually the first time is over tea or coffee at [a café]. Then it would be seeing them in their own environment, seeing them in the hallway, small talking and schmoozing. When we started to work with the intensivists, I would hang around for the noon rounds after discussing a patient with them. I would come to their morbidity and mortality rounds. I would blog about questions that they had for me that I didn't know the answer to. I would ask them questions about stuff that I probably could have found out on my own, but I wanted them to know that I was willing to learn from them and that this was not an issue of power balance. [Participant 4]

Spend time building relationships ... celebrate successes, engage the people that you will be working with and make them realize the importance of it at the outset. Engage them in step one and not to make something that authoritarian or don't come in and pretend you are the expert and they need to learn and how can we learn together to make sure patients really are getting the antimicrobials and minimizing the risk of collateral damage. The personal relationship part and the personal interaction between myself and the clinicians are working well and that's just really about meeting people where they are and listening and talking and them knowing that it's a safe environment, it's 
nonjudgmental and that their clinical expertise is recommended and I am always going to defer to their expertise. [Participant 2]

I really think that face-to-face conversation [during prospective audit and feedback] that we're having rather than leaving notes in the chart, I think that actually is working well because there's so much more you can learn in that interaction that is really valuable to have with the team. I think that's actually something our program has done very well-working on relationshipbuilding with the way we do stewardship. [Participant 1]

We have strategized to make them a stakeholder, so make them as equal participants and make them responsible partly for the other results also. So I can say in immune-compromised hosts "why don't we develop a protocol?" and we involve literally everyone so that the protocol that is developed, everyone involved owns that protocol. [Participant 6]

\section{Rapidly Establishing a Track Record}

The third theme reflected the process by which the antimicrobial stewards gained credibility. It involved considering how best to overcome the possible reluctance and resistance of prescribers in the ICU to changing their current antimicrobial practices so as to minimize the use of unnecessary broadspectrum antimicrobials and how best to influence the uptake of rational antimicrobial use. Reluctance and resistance were reflected by the perceptions of some prescribers that the key goal of the antimicrobial stewardship program was to reduce cost at the expense of quality and that their current practices were appropriate for their patient population. Over time, the antimicrobial stewards were able to demonstrate that antimicrobial use and positive patient outcomes were associated with a reduction in costs through prospective auditing of and feedback about antimicrobial prescribing practices. The demonstration that appropriate antimicrobial use was in the "best interest of the patient" was perceived by the antimicrobial stewards as instrumental in enabling the ICU clinicians to discern whether their patients required antibiotics, and if so, which one(s). This situation is illustrated in the following excerpts.

So I really do think our prospective audit and feedback within the ICU is something that works better than most people probably anticipated when it first started. That the culture shift and the acceptance and the sort of integration into being part of everyday care and expectations have been sort of the biggest uptake and success. [Participant 5]

When we initially started there was a lot of reluctance and resistance to this approach. "We know it all. We have been taking care of this patient for 30 years, and what do you guys know?" Now it has come to a point where they look at the antibiotic profile and say to themselves "this is what we can take off". From a total stone-walling they have come to realize over the course of time two things: that the use of antibiotics is necessary [and] we are their partners. We are not there to police them-we are not there to tell them "this is wrong". That has been our biggest impediment: lack of recognition. Now we have a track record, we have shown that we have cut down the costs without cutting down the quality of the patient care, so people are taking it more seriously. [Participant 6]

Gaining an understanding of the physicians' context and culture was another key process in establishing a track record and being closely aligned with prescribers. The first step of this process was to gain insight, referred to as "scouting". This involved understanding the unit's current state, what needed improving, and how best to integrate and improve evidencebased antimicrobial use in daily practice. The antimicrobial stewards explained that "a one size fits all" program was not the best way to approach implementation. The stewards were mindful and respectful when working with the ICU clinicians, tailoring the program according to each ICU's culture and context.

First thing is to do scouting, you go in and ask are there are any issues, if you have any what do you see, how you think you promote working, what do you think is the best way to integrate or improve our practices, and how can we help? If you take that approach then it is more likely to work as compared to just going there "so listen tomorrow our pharmacist will be coming in your team meeting and will be looking at your antibiotics", not Big Brother is watching type approach, that doesn't work in the long run. [Participant 6]

It's partly an art, how to articulate your recommendation to the prescriber and have good discussion, obviously for the sake of the patient, because we're trained very differently. Our thoughts could be different so how do you make that happen? How do you connect and understand each other and not be offended just because someone said something that may not be the same as your opinion. I think that big piece is very important. [Participant 3]

I think different units have different cultures in terms of best practices, evidence-based practice, and how antibiotics are perceived, used. Another factor is our ability to choose interventions wisely that would appeal to different units to take on an antimicrobial stewardship initiative. So it's the choice of the intervention. [Participant 4] 


\section{DISCUSSION}

This study sought to gain insight into antimicrobial stewards' perceptions and experiences of physicians' attitudes and behaviours related to antimicrobial prescribing within ICU settings. The study yielded 3 prominent themes: getting the right people on board, building collegial relationships, and then rapidly establishing a track record. Specifically, the study showed that influencing individual behaviours related to antimicrobial use was contingent upon the ability of antimicrobial stewards to first tailor their strategies to the individuals and the local contexts of participating units, and then demonstrate the impact of the intervention on relevant clinical outcomes and, to a lesser extent, cost.

The results elucidated the role and mechanisms that the program leader and other antimicrobial stewards used to influence other clinicians to engage in effective antimicrobial utilization. For example, the role that the antimicrobial stewards played was similar to the concepts of influentials as described in the Social Influence Theory ${ }^{21}$ and innovators as described in the Diffusion of Innovation Theory. ${ }^{22}$ Consistent with results concerning the importance of gaining credibility to influence the uptake of effective antimicrobial use, the Diffusion of Innovation Theory emphasizes that the status of an innovator as a reputable source is earned and maintained by technical competence, social accessibility, and conformity with the system's norms. ${ }^{22}$ Furthermore, the mechanisms employed by the antimicrobial stewards included using social influence and information transfer to enhance the uptake of effective antimicrobial use. Both the Social Influence Theory and the Diffusion of Innovation Theory propose that social influence is the primary mechanism used by influentials to change behaviour and social norms. ${ }^{21,22}$ Using social influences and role modelling, an influential is able to convince the target audience by sharing information about evidence-informed practices. Influentials identify nonconforming practices as outdated, not supported by research, and no longer accepted by colleagues and peers. ${ }^{21}$ Finally, the results reported here add to the evolving body of literature concerning the important role of leadership. ${ }^{22,28}$ Engaging senior leadership within and beyond the unit before initiating the intervention was crucial to the success of the program, enabling antimicrobial stewards to integrate within the clinical culture more smoothly and effectively.

There are ongoing challenges in balancing the need to ensure appropriate therapy to treat documented and presumed infection with the aim of minimizing antimicrobial use to avoid adverse drug events and emergence of antimicrobial resistance. ${ }^{29-34}$ In response to these challenges, antimicrobial stewardship programs, which require organizational change, are growing in a number of clinical settings within and beyond hospitals globally. ${ }^{35,36}$ This type of organizational change relies on modifying individuals' behaviour. Furthermore, broad variability in antimicrobial practices has been well described. ${ }^{29-31}$ This variability may relate to heterogeneity in individual knowledge and organizational culture (within a unit or hospital) related to antimicrobial use, but it may also be affected by other influences not yet elucidated (e.g., risk assessment and tolerance). ${ }^{37}$ In the context of implementing an antimicrobial stewardship program, therefore, engagement at the leadership level will not guarantee success at the individual level, in part because clinicians may not be ready for a change in their practices.

These findings should be interpreted in light of the following limitations. First, the transferability of the study findings to other settings may be limited, as the study participants were drawn from 3 urban teaching hospitals. Second, the data analyzed were from interviews conducted with the antimicrobial stewards and self-reporting of their perceptions on mechanisms of influence; interviewing the recipients of the stewardship interventions would be additionally informative. Third, the sample drew from physicians and pharmacists only and did not include other health care professionals (e.g., nurses) who also have an active role in antimicrobial stewardship programs.

\section{CONCLUSIONS}

The findings presented here reveal the importance of ensuring that the right people are engaged in influencing the uptake of effective antimicrobial use, the need to build effective, culturespecific relationships with stakeholders, and the importance of rapidly establishing credibility. These results highlight how team members tailored their strategies to individual clinicians and the local contexts of participating units and then gained credibility by demonstrating the impact of the antimicrobial stewardship program on clinical outcomes and cost. Engagement of senior leadership, to endorse and invest in the program, added to the antimicrobial stewards' credibility and their ability to influence the uptake of effective antimicrobial use. Collectively, these results offer insight into processes and mechanisms of influence employed by antimicrobial stewards to enhance clinicians' use of these drugs, which can inform future implementation of antimicrobial stewardship program and strategies for organizational change in hospitals.

\section{References}

1. Antibiotic resistance threats in the United States, 2013. Atlanta (GA): Centers for Disease Control and Prevention; 2013 [cited 2014 June 16]. Available from: www.cdc.gov/drugresistance/threat-report-2013/index.html

2. Antimicrobial resistance: global report on surveillance 2014. Geneva (Switzerland): World Health Organization; 2014 [cited 2014 June 16]. Available from: www.who.int/drugresistance/documents/surveillancereport/en

3. Charani E, Holmes AH. Antimicrobial stewardship programmes: the need for wider engagement. BMJ Qual Saf. 2013;22(11):885-7.

4. Davey P, Brown E, Charani E, Fenelon L, Gould IM, Holmes A, et al. Interventions to improve antibiotic prescribing practices for hospital inpatients. Cochrane Database Syst Rev. 2013;4:CD003543.

5. Liew YX, Chlebicki MP, Lee W, Hsu LY, Kwa AL. Use of procalcitonin (PCT) to guide discontinuation of antibiotic use in an unspecified sepsis is an antimicrobial stewardship program (ASP). Eur J Clin Microbiol Infect Dis. 2011; 30(7):853-5.

6. Charani E, Castro-Sanchez E, Sevdalis N, Kyratsis Y, Drumright L, Shah N, et al. Understanding the determinants of antimicrobial prescribing within hospitals: the role of "prescribing etiquette". Clin Infect Dis. 2013;57(2):188-96. 
7. Vincent JL, Rello J, Marshall J, Silva E, Anzueto A, Martin CD, et al. International study of the prevalence and outcomes of infection in intensive care units. JAMA. 2009;302(21):2323-9.

8. Mauldin PD, Salgado CD, Hansen IS, Durup DT, Bosso JA. Attributable hospital cost and length of stay associated with health care-associated infections caused by antibiotic-resistant gram-negative bacteria. Antimicrob Agents Chemother. 2010;54(1):109-15.

9. Roberts RR, Hota B, Ahmad I, Scott RD 2nd, Foster SD, Abbasi F, et al. Hospital and societal costs of antimicrobial-resistant infections in a Chicago teaching hospital: implications for antibiotic stewardship. Clin Infect Dis. 2009;49(8):1175-84.

10. McKinnell JA, Kunz DF, Chamot E, Patel M, Shirley RM, Moser SA, et al. Association between vancomycin-resistant Enterococci bacteremia and ceftriaxone usage. Infect Control Hosp Epidemiol. 2012;33(7):718-24.

11. Get smart: know when antibiotics work. Atlanta (GA): Centers for Disease Control and Prevention; 2014 [cited 2014 Jun 16]. Available from: www.cdc.gov/getsmart/community/index.html

12. Hopkins S. Improving antimicrobial stewardship and surveillance: the Chennai Declaration. BMJ. 2013;346:f591

13. Carlet J, Collignon P, Goldmann D, Goossens H, Gyssens IC, Harbarth S, et al. Society's failure to protect a precious resource: antibiotics. Lancet. 2011;378(9788):369-71.

14. Doron S, Nadkarni L, Price LL, Lawrence K, Davidson LE, Evans J, et al. A nationwide survey of antimicrobial stewardship practices. Clin Ther. 2013; 35(6):758-765.e20.

15. Xu R, Polk RE, Stencel L, Lowe DK, Guharoy R, Duggal RW, et al. Antibiogram compliance in University Health System Consortium participating hospitals with Clinical and Laboratory Standards Institute guidelines. Am J Health Syst Pharm. 2012;69(7):598-606.

16. Tamma PD, Cosgrove SE. Antimicrobial stewardship. Infect Dis Clin North Am. 2011;25(1):245-60.

17. Ghafur A, Mathai D, Muruganathan A, Jayalal JA, Kant R, Chaudhary D, et al. The Chennai declaration: a roadmap to tackle the challenge of antimicrobial resistance. Indian J Cancer. 2013;50(1):71-3.

18. Dresser L, Nelson S. Practice spotlight: pharmacists in an antimicrobial stewardship program. Can J Hosp Pharm. 2010;63(4):328-9.

19. Antworth A, Collins CD, Kunapuli A, Klein K, Carver P, Gandhi T, et al. Impact of an antimicrobial stewardship program comprehensive care bundle on management of candidemia. Pharmacotherapy. 2013;33(2):137-43.

20. MacDougall C, Polk, RE. Antimicrobial stewardship programs in health care systems. Clin Microbiol Rev. 2005;18(4):638-56.

21. Mittman BS, Tonesk X, Jacobson PD. Implementing clinical practice guidelines: social influence strategies and practitioner behavior change. QRB Qual Rev Bull. 1992;18(12):413-22.

22. Rogers EM. Diffusion of innovation. 5th ed. New York (NY): Simon and Schuster; 2003.

23. Flodgren G, Parmelli E, Doumit G, Gattellari M, O'Brien MA, Grimshaw J, et al. Local opinion leaders: effects on professional practice and health care outcomes. Cochrane Database Syst Rev. 2011;(8):CD000125.

24. Seto WH, Ching TY, Yuen KY, Chu YB, Seto WL. The enhancement of infection control in-service education by ward opinion leaders. Am J Infect Control. 1991;19(2):86-91.

25. Hsieh HF, Shannon SE. Three approaches to qualitative content analysis. Qual Health Res. 2005;15(9):1277-88.

26. Hickey G, Kipping C. Issues in research. A multi-stage approach to coding of data from open-ended questions. Nurs Res. 1996;4(1):81-91.

27. Required organizational practices handbook 2014. Ottawa (ON): Accreditation Canada; 2013 [cited 2014 Jun 16]. Available from: www.accreditation.ca/sites/ default/files/rop-handbook-2014-en.pdf

28. Suter E, Deutschlander S, Lait J. Using a complex systems perspective to achieve sustainable health care practice change. J Res Interprof Pract Educ. 2011;2(1):83-99.

29. Dunagan WC, Woodward RS, Medoff G, Gray JL 3rd, Casabar E, Smith MD, et al. Antimicrobial misuse in patients with positive blood cultures. Am JMed. 1989;87(3):253-9.
30. Gonzales R, Malone DC, Maselli JH, Sande MA. Excessive antibiotic use for acute respiratory infections in the United States. Clin Infect Dis. 2001; 33(6):757-62.

31. Fridkin SK, Steward CD, Edwards JR, Pryor ER, McGowan JE Jr, Archibald LK, et al. Surveillance of antimicrobial use and antimicrobial resistance in United States hospitals: project ICARE phase 2. Project Intensive Care Antimicrobial Resistance Epidemiology (ICARE) hospitals. Clin Infect Dis. 1999;29(2):245-52.

32. Malhotra-Kumar S, Lammens C, Coenen S, Van Herck K, Goossens H. Effect of azithromycin and clarithromycin therapy on pharyngeal carriage of macrolide-resistant streptococci in healthy volunteers: a randomised, doubleblind, placebo-controlled study. Lancet. 2007;369(9560):482-90.

33. Goossens H, Ferech M, Vander Stichele R, Elseviers M; ESAC Project Group. Outpatient antibiotic use in Europe and association with resistance: a crossnational database study. Lancet. 2005;365(9459):579-87.

34. Cosgrove SE, Sakoulas G, Perencevich EN, Schwabe MJ, Karchmer AW, Carmeli Y, et al. Comparison of mortality associated with methicillin-resistant and methicillin-susceptible Staphylococcus aureus bacteremia: a meta analysis. Clin Infect Dis. 2003;36(1):53-9.

35. Marr JJ, Moffet HL, Kunin CM. Guidelines for improving the use of antimicrobial agents in hospitals: a statement by the Infectious Diseases Society of America. J Infect Dis. 1988;157(5):869-76.

36. Dellit TH, Owens RC, McGowan JE Jr, Gerding DN, Weinstein RA, Burke JP, et al. Infectious Diseases Society of America and the Society for Healthcare Epidemiology of America guidelines for developing an institutional program to enhance antimicrobial stewardship. Clin Infect Dis. 2007;44(2):159-77.

37. Hulscher ME, Grol RP, van der Meer JW. Antibiotic prescribing in hospitals: a social and behavioural scientific approach. Lancet Infect Dis. 2010;10(3): $167-75$.

Lianne Jeffs, RN, PhD, is with the Keenan Research Centre, Li Ka Shing Knowledge Institute, St Michael's Hospital, and the Lawrence S Bloomberg Faculty of Nursing and the Institute of Health Policy, Management and Evaluation, University of Toronto, Toronto, Ontario.

Nisha Thampi, MD, MSc, FRCPC, is with the Children's Hospital of Eastern Ontario, Ottawa, Ontario.

Maria Maione, RN, MN, is with Professional Practice - Nursing Research Portfolio, St Michael's Hospital, Toronto, Ontario.

Marilyn Steinberg, RN, is with Mount Sinai Hospital, Toronto, Ontario.

Andrew M Morris, MD, SM, FRCPC, is with Mount Sinai Hospital, the University Health Network, and the Department of Medicine, University of Toronto, Toronto, Ontario.

Chaim M Bell, MD, PhD, is with Mount Sinai Hospital and the Department of Medicine, University of Toronto, Toronto, Ontario

Competing interests: None declared.

\section{Address correspondence to:}

Dr Lianne Jeffs

Keenan Research Centre

Li Ka Shing Knowledge Institute

St Michael's Hospital

30 Bond Street

Toronto ON M5B 1W8

e-mail: jeffs|@smh.ca

Funding: Lianne Jeffs receives partial funding for her research through the St Michael's Hospital Volunteer Association Chair in Nursing Research. Andrew Morris receives salary support from Mount Sinai Hospital and University Health Network for antimicrobial stewardship work. This study was supported solely by internal funding. 